\title{
How Environmental Regulations Affect the Efficiency of Green Technology Innovation?
}

\author{
Long Wei, Hu Zhang \\ School of Economics, Wuhan University of Technology, Wuhan, China \\ Email: 1435580865@qq.com
}

How to cite this paper: Wei, L., \& Zhang, H. (2020). How Environmental Regulations Affect the Efficiency of Green Technology Innovation? American Journal of Industrial and Business Management, 10, 507-521. https://doi.org/10.4236/ajibm.2020.103034

Received: January 20, 2020

Accepted: March 1, 2020

Published: March 4, 2020

Copyright () 2020 by author(s) and Scientific Research Publishing Inc. This work is licensed under the Creative Commons Attribution International License (CC BY 4.0).

http://creativecommons.org/licenses/by/4.0/

(c) (i) Open Access

\begin{abstract}
Green technology innovation is an effective driving force to achieve the optimization and upgrading of industrial structure. Environmental regulations principally behave in guiding green technology innovation activities. Based on the Super-Sbm-Dea efficiency model with undesirable output, this paper estimates the provincial-level efficiency of green industrial technology innovation (Gtie) in China from the aspects of technology development, technology transformation and industrial innovation value chain (IVC) from 2005 to 2015, and analyzes its dynamic trend with kernel density function. The conclusions are as follows: 1) Gtie is low and on the rise generally, and tends to decrease in the stages of technology development, achievement transformation and industrialization; in the stage of technology development, the gap between the eastern region and other regions of China tends to increase, while Gtie is on the contrary in the other stages. 2) Gtie spatial spillover is obvious. In the traditional panel model, the effects of command and public environmental regulations are obvious, while the roles of FDI and market regulations are opposite, and the impact of openness and economic development level is not significant. 3) Based on the analysis of Durbin model, market, public regulations and openness improve the efficiency directly. However, economic development level shows significant inhibition effect, while the role of the command regulations and FDI are not significant.
\end{abstract}

\section{Keywords}

Green Technology Innovation Efficiency, Innovation Value Chain, Space Spillover

\section{Introduction}

Technological innovation plays an important role in the process of continuous adjustment and optimization of the economic structure. However, the traditional 
technological innovation mode has many negative ecological effects, such as high energy consumption in per unit output value, low resource utilization rate, environmental pollution and so on. Therefore, to reduce material consumption, energy consumption, pollution emissions and improve production quality, green technology has become the key to create new kinetic energy and achieve high-quality development. The green technology innovation refers to a series of innovative activities in the process of production, operation and sales to reduce pollution emissions, energy consumption and enhance environmental competitiveness. This paper applies Gtie to represent the efficiency of green technology innovation, the enterprise has the purpose to invest in the development of green technology, and to apply green environmental protection patent technology and green process fully. Green technology innovation efficiency measures the ratio of green input and output in the innovation process. In the face of resource shortage and the arduous task of improving the ecological environment, the governments continue to strengthen the requirements of environmental regulations. A significant fact is that only a few enterprises spontaneously carry out green technology innovation activities for ideals and social responsibilities, while environmental regulations can guide green technology innovation activities in the market by institutional design under institutional incentives and constraints. Almost all enterprises will be affected by the standard, degree, range of environmental regulations to some degree. Therefore, it is necessary to analyze the impact of environmental regulations on China's industrial Gtie with the different types of regulations deeply from the perspective of spatial spillover. The impact of environmental regulations on Gtie has already become a hot topic. The existing research can be summarized as the following three clues: linear, nonlinear and uncertainty relationship theory.

Firstly, there exists a linear relationship. On the whole, the environmental regulations have a single promotion or inhibition effect on Gtie. The effect of environmental policies on Gtie through environmental patent was studied, and the results support Porter hypothesis, environmental policies promoted green technology innovation behavior significantly (Wang \& Cheng, 2013). The environmental regulations, increasing pollution control costs, production and operation constraints, caused crowding out green R\&D investment (Zhao, 2003). Regulations, which are in high density, stimulate green technology innovation positively (Frondelm et al., 2007), while the regulations inhibit the output of green technology innovation patents (Wagner, 2007).

Secondly, there is nonlinear argument. The effect of environmental regulations on Gtie is nonlinear, such as threshold effect. For example, regulations can improve the value of industrial ecological efficiency when the degree of administrative monopoly is at a specific threshold level significantly (Qiu \& Wang, 2018), while the impact is not significant from the perspective of intermediary effect to administrative monopoly when the threshold is crossed. In addition, scholars also analyze the role of environmental regulations from the perspective of manufacturing industry and different regions, and found that its effect on Gtie was inverted "U” (Liu \& Yuan, 2018; Zang \& Zhang, 2015). 
Thirdly, there is argument of uncertainty. The role of environmental regulations on Gtie will change with the different regulation tools, regional and industry differences. Command and market regulations promoted green product and process innovation significantly (Zhang, 2015), while the emission tax rate and the emission license price encouraged the Gtie of enterprises effectively (Xu et al., 2012). The role of environmental regulations on the green transformation of industry was studied from the perspective of the intermediary effect of green technology innovation (Peng \& Li, 2016). These show that the command regulations have no non-linear impact on it, while the higher economic incentive and voluntary awareness by promoting green technology innovation, the high level of command regulations can promote industrial green transformation and upgrade successfully. Different effects of environmental regulations in heterogeneous industries (Sen, 2015). From the perspective of significant differences among industries, the regulations promote the green products and process innovation of primary processing industry, and present the reverse conclusion in the mining and washing industry (Wang \& Guo, 2015). The regulations have the opposite effects on the Gtie in the short term and long term (Li et al., 2014). From a static perspective, the environmental regulations increase the cost burden of enterprises and weaken the innovation ability of regulated enterprises, while the reasonable environmental regulation can encourage enterprises to produce "innovation compensation effect" from a dynamic perspective (Porter, 1991; Porter \& Vander, 1995).

Shortcomings are mainly reminded in the field of environmental regulations on Gtie: 1) Most scholars use traditional innovation indicators (such as R\&D investment) to measure Gtie directly. 2) Some scholars calculate Gtie based on Two-stage Dea model without considering environmental factors and random noise, causing error results, which is difficult to accurately reflect the real level of efficiency. 3) The efficiency level of multiple decision-making units in the same period are examined, however, the dynamic evolution characteristics of Gtie among different year are not shown. 4) In the discussion of the different regulations on Gtie, some researchers focus on the direct effect of environmental regulations on Gtie, neglecting the dynamic externalities of regulations and innovation activities. Only a few numbers of scholars, have noticed the obvious facts above, conducting research on Gtie from the perspective of spatial differences, analyzing spatial spillover effects with Slm and Sem, ignoring the correlation effects of regulations itself, and the division of innovation chain needs to be improved (Liu et al., 2018; Wang et al., 2018).

This paper intends to research them based on the different environmental regulations tools, and divide them into command, market and public type respectively, and expands the research from the following aspects: 1) Construct green R\&D indicators to reflect the nature of Gtie effectively. 2) Three stages Dea model is adopted to effectively separate the influence of environmental factors on Gtie. 3) Use multivariate kernel density function to analyze the dynamic evolution of Chi- 
nese industrial Gtie. 4) Based on the spatial weight matrix of multi dimension, a Durbin model is used to integrate the interval correlation among various environmental regulations variables into the analysis of Gtie spillover effect, which may provide reference for selecting effective policies and multiple combinations of policies.

\section{Theoretical Framework and Mechanism Analysis}

Environmental regulations are relevant to environmental protection policy or implementation tools for solving the environmental problems formulated by the government in economic growth, the specific mechanism will be discussed separately from the three regulations.

The command environmental regulations, using the total amount standard, time limit and other standards, urge enterprises to close some production projects in a short period of time, reduces pollution emissions and energy consumption level directly, increasing investment caused by environmental protection and energy conservation under the effect of investment crowding out effects, thus promoting the green energy and production structure.

The market environmental regulations, using the transaction taxes and pollution charges, leading enterprises to choose their own optimal production scale in the cost-benefit analysis framework, which reduces unnecessary environmental pollution expenditure and achieves the optimal level of emissions.

The public environmental regulations, releasing the pressure of public opinion to enterprises by the environmental petition and complaint, enterprises carry out strategic green technology research and development, and provide green environmental protection products and services to meet the demand of green consumption under the consideration of social responsibility and strategic needs, which improves the efficiency and ability of green technology innovation indirectly, the analysis details show in Figure 1.

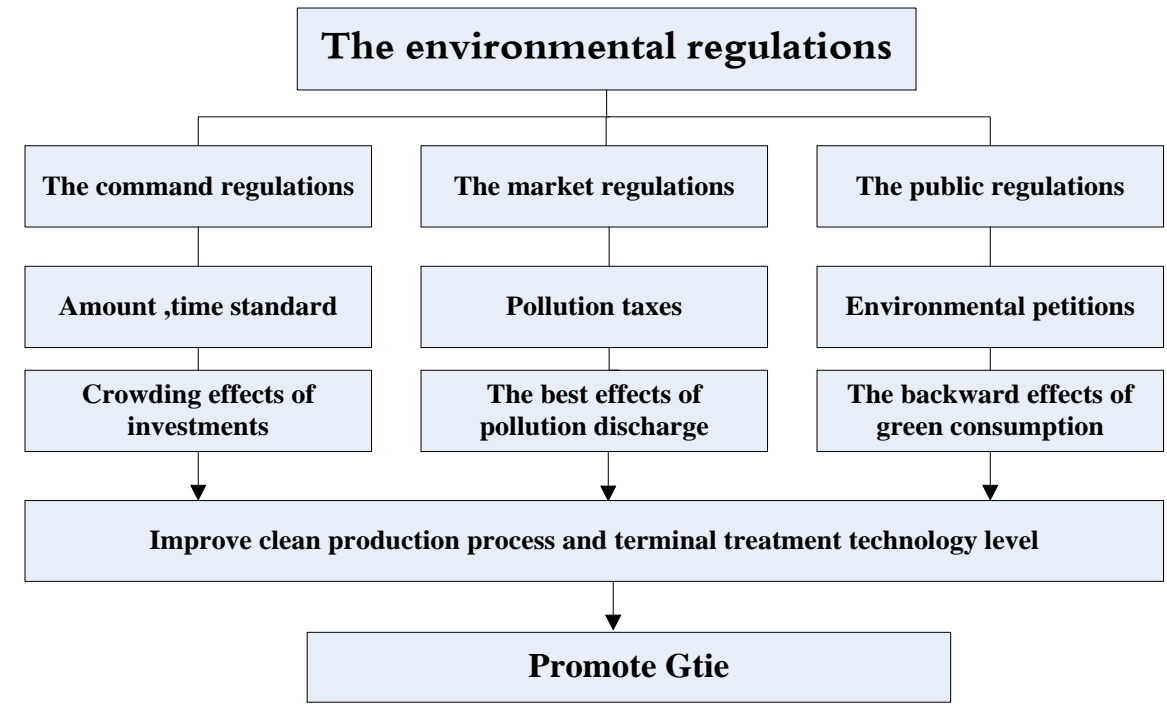

Figure 1. The impact mechanism of different environmental regulations on Gtie. 


\section{Efficiency Measurement and Analysis}

\subsection{Research Methods and Measurement Models}

In order to eliminate the impact of environmental factors and other random factors (all factors except scale, technology and management factors) on production efficiency, the three-stages Dea efficiency evaluation model was proposed (Fried et al., 2002). To separate the influence of environmental factors, this paper uses three-stage analysis framework as Dea-Sfa-Dea, the whole process is divided into three steps:

Step 1: Dea analysis stage: calculates the efficiency and slack.

Step 2: Use Sfa quasi regression to decompose the relaxation variables, stripping off the environmental factors and statistical noise, the adjustment formula are as follows:

$$
\begin{aligned}
X_{n i}^{A}= & X_{n i}+\left[\max \left(f\left(Z_{i} ; \hat{\beta}_{n}\right)\right)-f\left(Z_{i} ; \hat{\beta}_{n}\right)\right] \\
& +\left[\max \left(v_{n i}\right)-v_{n i}\right], \quad i=1,2, \cdots, I ; n=1,2, \cdots, N
\end{aligned}
$$

$X_{n i}^{A}$ is the adjusted input, $X_{n i}$ is the initial input, $\max \left(f\left(Z_{i} ; \hat{\beta}_{n}\right)\right)-f\left(Z_{i} ; \hat{\beta}_{n}\right)$ is the express to adjust the decision-making unit in the same state, and $\max \left(v_{n i}\right)-v_{n i}$ is the express to adjust the statistical noise of all decision-making units in the same level.

Step 3: Re-measure the adjusted input variables and original output variables to get the true efficiency value without environmental factors and random errors.

The Super-efficiency model, is used to measure the efficiency of decision-making units in the stage without undesirable output (Andersen et al., 1993), there are " $n$ " decision-making units, the input and output variables amount are " $m$ " and " $s$ " respectively, and the constraint set is shown in Formula (2). The slack variables were introduced into the objective function directly, forming the non radial and non oriented Sbm (Tone, 2001). The inefficiency level in Sbm is measured from the input and output perspectives, based on the basic Sbm, the Sbm-undesirable model is adopted in the stage with undesired output, there are three variables, input $X_{i}$ expected output $Y_{e i}$ and undesired output $Y_{u r}$ the possible set is defined as $P_{\mathrm{i}}\left(X_{i}, Y_{e}, Y_{u i}\right)$, the constraint set is shown in Formula (3).

1) Super efficiency model

$$
\begin{aligned}
& \text { s.t }\left\{\begin{array}{l}
\theta X_{k}-\sum_{\substack{i=1 \\
j \neq k}}^{n} X_{j} \lambda_{j} \geq 0 \\
-Y_{k}+\sum_{\substack{i=1 \\
j \neq k}}^{s} Y_{j} \lambda_{j} \geq 0 \\
\lambda_{j} \geq 0, j=1,2, \cdots, n
\end{array}\right. \\
& X_{k}=\left(x_{1 k}, \cdots, x_{m k}\right), Y_{k}=\left(y_{1 k}, \cdots, y_{s k}\right)
\end{aligned}
$$

2) Sbm undesirable efficiency model 


$$
\begin{aligned}
& \min \rho^{*}=\frac{1-(1 / m) \sum_{i=1}^{m}\left(s_{i}^{-} / x_{i k}\right)}{1-1 /\left(s_{1}+s_{2}\right) \sum_{r=1}^{s_{1}} s_{r}^{e} / y_{r o}^{e}+\sum_{r=1}^{s_{2}} s_{r}^{u} / y_{r o}^{u}} \\
& \text { s.t }\left\{\begin{array}{l}
x_{o}=X \lambda+s^{-} \\
y_{o}^{e}=Y^{e} \lambda-s^{e} \\
y_{o}^{u}=Y^{u} \lambda+s^{u} \\
s^{-} \geq 0, s^{e} \geq 0, s^{u} \geq 0, \lambda \geq 0
\end{array}\right.
\end{aligned}
$$

In Formula (2), $\theta$ is the range angel, and $X_{k}, Y_{k}$ are the input and output matrix respectively. In formula (3), $\mathrm{S}^{-}, S^{e}$ and $S^{u}$ are input, expected and undesirable output relaxation respectively, $\rho^{\star}$ decreases strictly and ranges from 0 to $1, \mathrm{dmu}$ is effective when $\rho^{*}$ equal to 1 and the three relaxation values equal to 0 , while it is ineffective when $\rho^{\star}$ less than 1 .

\subsection{Data and Variables}

Innovation value chain, which be used to analyse the innovation activities in enterprises originally (Hansen \& Birkinshaw, 2008), the intermediate test link is added in technology development and industrialization stages for the innovation reality. The three links focus on knowledge innovation, process innovation and product innovation respectively, the efficiency, divided into technology development, achievement transformation and industrialization stage is calculated respectively (Liu et al., 2015).

The green $\mathrm{R} \& \mathrm{D}$ index is constructed to reflect the essential characteristics of Gtie, and using methods adapted as scholars (Yu \& Liu, 2013), by using the segmented efficiency multiplication replacing whole Gtie. The following is a detailed table of variable indicator selection and related indicator descriptions, all variables are listed in Table 1, P1, P2 and P3 represent technological, development technology transformation and industrialization, the main indicators are explained in detail as follows, and the indicators not explained are all from statistical yearbooks and official websites.

In Table 1, Total green R\&D: the investment stock of three wastes investment management is used as the substitute for green $\mathrm{R} \& \mathrm{D}$ ( $\mathrm{Li}, 2017)$. The investment in environmental pollution control can reflect the investment intensity of enterprises in the region in green production technology and terminal treatment technology, from which the level of green R\&D expenditure can be inferred to a certain extent. Government support: the government support is measured by the funds raised by science and technology and the internal expenditure of R\&D funds. The education level is replaced by average years of education. Comprehensive index of environment: the environmental comprehensive index is used as undesirable index by making the logarithm of the sum of industrial wastewater, sulfur dioxide, smoke and dust emissions, general industrial solid waste and the logarithm of industrial added value as a quotient (Luo \& Liang, 2016), which can reflects the cost of environmental pollution in the process of innovation activities directly. 
Table 1. Variables selected in chain of innovation.

\begin{tabular}{rlll}
\hline Stages & \multicolumn{1}{c}{ Input varibles } & \multicolumn{1}{c}{ Output varibles } & Control varibles \\
\hline P1 & $\begin{array}{l}\text { Total green R\&D } \\
\text { Full time equivalent of R\&D personnel }\end{array}$ & Valid invention patent & $\begin{array}{l}\text { Education } \\
\text { Govrnment } \\
\text { support }\end{array}$ \\
P2 & $\begin{array}{l}\text { Scientific, technological activities peoples } \\
\text { Valid invention patents } \\
\text { New product development expenditure }\end{array}$ & $\begin{array}{l}\text { New product development } \\
\text { projects } \\
\text { New type, appearance } \\
\text { patents authorization }\end{array}$ & Economic level \\
& $\begin{array}{l}\text { New product development projects } \\
\text { New type ,appearance patents } \\
\text { authorization }\end{array}$ & $\begin{array}{l}\text { New product sales revenue } \\
\text { Comprehensive index of } \\
\text { environment }\end{array}$ & Market structure \\
\hline
\end{tabular}

Market structure: the market structure is measured by the ratio of the total output value of industries above designated size to the number of local enterprises above designated size, and the indicators are lagged behind for one period. The indexes were selected from the China Science and Technology Statistical Yearbook, China Environment Statistical Yearbook, Industrial Enterprise Science and Technology Activity Statistical Yearbook, etc, covering the period from 2005 to 2016 .

\subsection{Analysis of Calculation Results}

In Table 2, the provincial efficiency has improved in three stages during the investigation period. After stripping the influence of environmental factors, Hebei and Jiangsu, without investment redundancy, are at the forefront of production in three stages. To some extent, it reflects that the strength of scientific and technological research and development, the structure of technology market and the industrial environment play an important role in promoting Gtie. The efficiency in transformation stage in Gansu, Qinghai and Xinjiang is high, while the industrialization efficiency is low, which leads to the low efficiency level. The reason is that there are unique advantages in technological research and development, market maturity and appropriate industrialization environment in the eastern region. The difficulty of changing the potential price in green patents technology into specific product production and obtaining market recognition is increasing gradually. To consider the dynamic evolution of Gtie in each province furtherly, nonparametric kernel density analysis method is adopted for the three annual profiles of 2007, 2011 and 2015, as shown in Figure 2.

Based on Figure 2, there is following remarkable characteristics. Firstly, kernel density function tends to move to the right during the inspection period, indicating that the efficiency of industrial Gtie in China is growing. Secondly, the annual difference is obvious on the peak value, which shows that the gap between industrial Gtie and interval is increasing. Thirdly, the wave peak distribution shows polarization, and the main part distributes on the left low efficiency range, indicating that most provinces are in low efficiency level, and a few provinces are in high value area. 
Table 2. The provincial green technology innovation efficiency in China.

\begin{tabular}{|c|c|c|c|c|c|c|c|c|}
\hline \multirow{2}{*}{$\begin{array}{c}\text { Province/Year } \\
\text { Stages }\end{array}$} & \multicolumn{3}{|c|}{$2005-2007$} & \multirow[b]{2}{*}{$\mathrm{E}(07)$} & \multicolumn{4}{|c|}{$2013-2015$} \\
\hline & E1 (05) & E2 (06) & E3 (07) & & E1 (13) & E2 (14) & E3 (15) & E (15) \\
\hline Bei Jing & 1 & 0.71 & 0.643 & 0.456 & 0.99 & 0.886 & 0.813 & 0.713 \\
\hline Tian Jin & 0.837 & 0.719 & 0.719 & 0.433 & 0.932 & 0.87 & 0.824 & 0.668 \\
\hline He Bei & 1.062 & 1.064 & 1 & 1.13 & 1.05 & 1.028 & 1 & 1.079 \\
\hline Shan Xi & 0.874 & 0.812 & 0.746 & 0.529 & 0.96 & 0.938 & 0.835 & 0.752 \\
\hline Inner Mongolia & 0.806 & 0.676 & 0.63 & 0.343 & 0.953 & 0.863 & 0.754 & 0.62 \\
\hline Liao Ning & 0.908 & 0.796 & 0.781 & 0.564 & 0.934 & 0.917 & 0.857 & 0.734 \\
\hline Ji Lin & 0.854 & 0.779 & 0.721 & 0.48 & 0.93 & 0.888 & 0.805 & 0.664 \\
\hline Hei Long Jiang & 0.85 & 0.739 & 0.734 & 0.461 & 0.907 & 0.854 & 0.796 & 0.617 \\
\hline Shang Hai & 0.952 & 0.778 & 0.779 & 0.577 & 0.931 & 0.915 & 0.847 & 0.721 \\
\hline Jiang Su & 1.183 & 1.3 & 1 & 1.538 & 1.172 & 1 & 1 & 1.172 \\
\hline Zhe Jiang & 1.027 & 1.012 & 0.903 & 0.939 & 1.068 & 0.898 & 0.942 & 0.904 \\
\hline An Hui & 0.908 & 0.783 & 0.8 & 0.569 & 0.957 & 0.888 & 0.889 & 0.756 \\
\hline Fu Jian & 0.79 & 0.648 & 0.641 & 0.328 & 0.91 & 0.821 & 0.839 & 0.627 \\
\hline Jiang Xi & 0.812 & 0.664 & 0.651 & 0.351 & 0.977 & 0.877 & 0.883 & 0.757 \\
\hline Shan Dong & 0.845 & 0.695 & 0.711 & 0.418 & 0.884 & 0.806 & 0.762 & 0.543 \\
\hline He Nan & 0.828 & 0.707 & 0.706 & 0.413 & 0.924 & 0.853 & 0.82 & 0.646 \\
\hline Hu Bei & 0.959 & 0.862 & 0.827 & 0.684 & 0.918 & 0.861 & 0.81 & 0.64 \\
\hline Hu Nan & 0.788 & 0.648 & 0.632 & 0.323 & 0.919 & 0.873 & 0.817 & 0.656 \\
\hline Guang Dong & 1.037 & 1 & 1 & 1.037 & 1 & 0.843 & 1 & 0.843 \\
\hline Guang Xi & 0.892 & 0.778 & 0.746 & 0.518 & 0.934 & 0.866 & 0.817 & 0.661 \\
\hline Hai Nan & 0.76 & 0.696 & 0.587 & 0.311 & 0.947 & 1.043 & 0.824 & 0.814 \\
\hline Chong Qing & 0.796 & 0.648 & 0.647 & 0.334 & 0.942 & 0.892 & 0.887 & 0.745 \\
\hline Si Chuan & 0.847 & 0.707 & 0.719 & 0.431 & 0.908 & 0.846 & 0.854 & 0.656 \\
\hline Gui Zhou & 0.86 & 0.776 & 0.801 & 0.535 & 0.95 & 0.872 & 0.821 & 0.68 \\
\hline Yu Nan & 0.783 & 0.671 & 0.625 & 0.329 & 0.932 & 0.859 & 0.812 & 0.65 \\
\hline Shan Xi & 0.87 & 0.746 & 0.756 & 0.491 & 0.902 & 0.861 & 0.824 & 0.64 \\
\hline Gan Su & 0.781 & 0.641 & 0.603 & 0.302 & 0.956 & 0.86 & 0.772 & 0.635 \\
\hline Qing Hai & 0.78 & 0.674 & 0.583 & 0.306 & 0.998 & 0.938 & 0.785 & 0.735 \\
\hline Ning Xia & 0.8 & 0.682 & 0.635 & 0.346 & 0.997 & 0.868 & 0.782 & 0.677 \\
\hline Xin Jiang & 0.803 & 0.677 & 0.652 & 0.355 & 0.976 & 0.869 & 0.804 & 0.682 \\
\hline
\end{tabular}




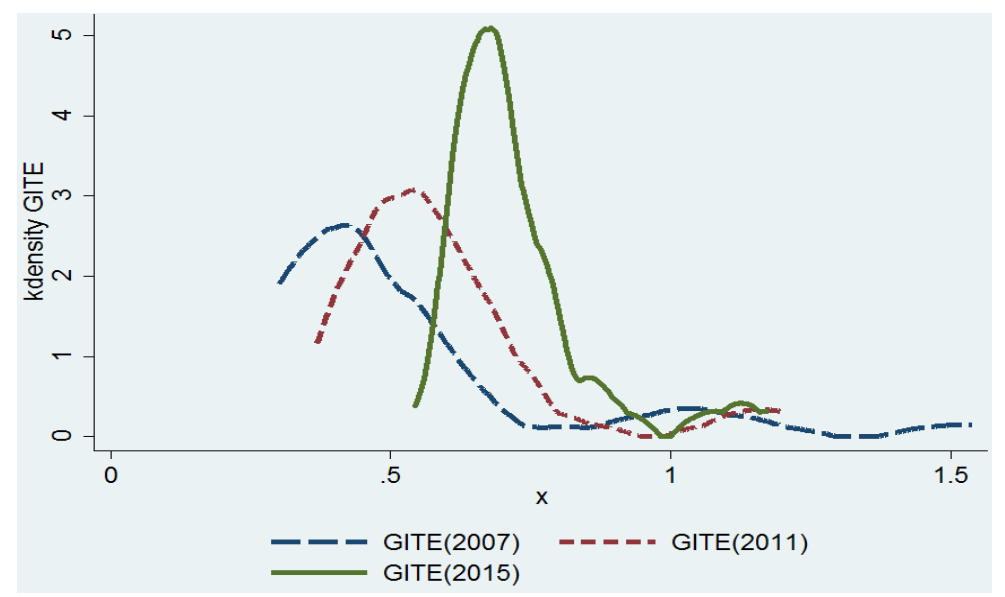

Figure 2. The provincal dynamic evolution of Gtie in China.

\section{The Imacts of Different Environmental Regulations on Gtie}

Based on the overall gtie calculated above, this part will analyze the impact of different environmental regulation policies on the efficiency of green technology innovation, the spillover effect of gtie, and the direct, indirect and total effects of various environmental regulation policies on gtie from a spatial perspective.

To investigate the efficiency of environmental regulations on green technology innovation, spatial autocorrelation test of variables is the premise of spatial autocorrelation analysis. This paper uses the common global Moran's index as follows:

$$
\text { Moran's I }=\frac{n}{\sum_{i=1}^{n}\left(Y_{i}-\bar{Y}\right)^{2}} \frac{\left(Y_{j}-\bar{X}\right)\left(Y_{i}-\bar{Y}\right) * \sum_{i=1}^{n} \sum_{j=1}^{n} w_{i j}}{\sum_{i=1}^{n} \sum_{j=1}^{n} w_{i j}}
$$

In Formula (4), $Y_{i}$ and $Y_{j}$ represent the observed values of region " $i$ ", " $j$ " respectively, " $n$ " is the number of areas studied and analyzed. $W_{i j}$ is the corresponding spatial weight matrix, which represents the degree of dependence and correlation of objects in space. The figure below is the Moran's index value, as shown in Table 3 (limited to space, partial display in the article).

Based on Table 3, there is a significant spatial autocorrelation in the provincal industrial Gtie. It is necessary to consider the spatial effect factors in the model setting, and investigate the impact of the interaction between environmental regulationss on Gtie. According to the general practice, the ratio of simultaneous environmental protection investment in regional GDP is selected as the command regulations index. The market regulations focuses on the price guidance under cost-benefit, adopting environmental tax and subsidy mostly, so the ratio of total income of pollution discharge fee in industrial value added is selected as the index (Xu et al., 2013). The public regulations refer to the participation of environmental protection and the expression of environmental interests to non-governmental organizations. The ratio of the number of environmental petitions in regional population is selected to measure the regulations level (Zhang et al., 2015). In addition, other factors also have an important impact on the Gtie. Openness and 
Table 3. The spatial autocorrelation of Gtie.

\begin{tabular}{ccccccc}
\hline Time & 2007 & 2008 & 2011 & 2012 & 2014 & 2015 \\
\hline Moran's I & 0.109 & 0.109 & 0.198 & 0.232 & 0.255 & 0.154 \\
E (I) & -0.034 & -0.034 & -0.034 & -0.034 & -0.034 & -0.034 \\
p-value* & 0.079 & 0.029 & 0.011 & 0.005 & 0.003 & 0.032 \\
\hline
\end{tabular}

economic level are selected as the control variables of the model. OPEN: the regional openness affects the flow of resources in the region directly. The openness is expressed by the proportion of the total import and export in the GDP of each province (Huang et al., 2015). Economic level: it is characterized by the ratio of total regional GDP in local population. Foreign direct investment: Investment will bring technology spillover in some degree by the introduction and utilization of foreign advanced technology, however, the crowding effects to domestic enterprises shouldn't be ignored, the level of fdi measured by the proportion of the total investment for foreign-funded enterprises in the provincal GDP, all data used were logarithmized before data processing to eliminate the heteroscedasticity

Space Durbin mode

$$
\begin{aligned}
G T I E_{i t}= & \rho \sum_{j=1}^{30} W_{i j} G t i e_{i t}+\gamma_{1} \sum_{j=1}^{30} W_{i j}\left(E R_{1}, E R_{2}, E R_{3}\right)_{i t}+\gamma_{2} \sum_{j=1}^{30} W_{i j} F D I_{i t}+\gamma_{3} \sum_{j=1}^{30} W_{i j} O P E N_{i t} \\
& +\gamma_{4} \sum_{j=1}^{30} W_{i j} P G D P_{i t}+\mu_{t}+\lambda_{t}+\omega_{i t}, \quad \mu \sim N\left(0, \sigma^{2} I_{i}\right), \omega_{i t} \sim N\left(0, \sigma^{2} I_{n}\right) .
\end{aligned}
$$

In Formula (5), $\rho$ is the spatial autoregressive coefficient, $W_{i j} G_{t i} e_{i t}$ is space lag term. $\gamma_{1}$ is marginal contribution of adjacent explanatory variables, $v, u$ is the heterogeneity.

1) Geographical adjacency matrix. It is the most intuitive and basic form to represent the dependency of geographical units in space. The definition formula is as follows: $w_{i j}=1$, if adjacent boundary exists, else $w_{i j}=0$.

2) Geographic distance weight matrix. To make up for the defect of adjacency matrix, the spherical distance between provincial capitals is selected as the basis for constructing the weight of geographical distance, as shown in Formula (6).

$$
\begin{aligned}
d_{i j}= & R * \arccos \left[\cos \left(\alpha_{i} /(180 / P I)\right) \cos \left(\alpha_{j} /(180 / P I)\right) \cos (\beta /(180 / P I))\right. \\
& \left.+\sin \left(\alpha_{i} /(180 / P I)\right) \sin \left(\alpha_{j} /(180 / P I)\right)\right], \quad W_{i j}=1 /\left(d_{i j}\right)^{2}
\end{aligned}
$$

Before regression analysis, the stationarity of the explained variable and the main explained variables is tested, all variables passed the test of stationarity according to Table 4. The fixed effect model in Durbin spatial was selected by Hausmann test. The market and public environment regulations, openness and economic level have a significant positive impact on local Gtie under the undesirable output from Table 5, the commm and environmental regulations, market environmental regulations and openness of neighboring areas have significant positive effects on local Gtie. The spatial autoregressive coefficient is 0.152 , which is positive at the level of $1 \%$ significantly, There are significant spatial spillover effects in provinces. 
Table 4. Stationarity test.

\begin{tabular}{ccccc}
\hline Variables & Ctie & ER1 & ER2 & ER3 \\
\hline $\mathrm{Z}$ (ht test) & -1.4999 & -10.7202 & -1.3531 & -4.767 \\
$\boldsymbol{p}$-value & 0.0668 & 0.0000 & 0.0880 & 0.0000 \\
\hline
\end{tabular}

Table 5. Regression results of spatial Durbin model.

\begin{tabular}{|c|c|c|c|c|c|}
\hline & PDM & \multicolumn{2}{|c|}{ SDM (W1) } & \multicolumn{2}{|c|}{ SDM (W2) } \\
\hline Variables & Panel & Main & Wx & Main & Wx \\
\hline \multirow[t]{2}{*}{ ER1 } & $0.181^{\star}$ & -0.0237 & $0.503^{* * *}$ & -0.0204 & 0.290 \\
\hline & $(0.0935)$ & $(0.0807)$ & $(0.143)$ & $(0.0838)$ & $(0.183)$ \\
\hline \multirow[t]{2}{*}{ ER2 } & $-0.643^{*}$ & $0.640^{\star}$ & $-1.581^{\star \star}$ & 0.503 & $-1.179^{*}$ \\
\hline & $(0.385)$ & $(0.370)$ & $(0.632)$ & $(0.374)$ & $(0.620)$ \\
\hline \multirow[t]{2}{*}{ ER3 } & $2.203^{* * *}$ & $1.590^{\star * *}$ & -0.0339 & $1.087^{*}$ & 1.859 \\
\hline & $(0.695)$ & $(0.587)$ & (1.156) & $(0.603)$ & (1.219) \\
\hline \multirow[t]{2}{*}{ OPEN } & 0.365 & $1.079^{* *}$ & $-4.048^{* * *}$ & $1.556^{* * *}$ & $-2.848^{\star \star \star}$ \\
\hline & $(0.571)$ & $(0.492)$ & $(0.779)$ & $(0.521)$ & $(0.799)$ \\
\hline \multirow[t]{2}{*}{ FDI } & $-16.51^{\star * *}$ & 0.0206 & 0.123 & -0.0264 & -0.243 \\
\hline & (5.328) & $(0.120)$ & $(0.232)$ & $(0.128)$ & $(0.333)$ \\
\hline \multirow[t]{2}{*}{ PGDP } & -0.0173 & $-12.46^{\star *}$ & 2.928 & $-8.403^{\star}$ & -12.28 \\
\hline & $(0.148)$ & $(4.859)$ & (9.679) & $(4.626)$ & $(9.436)$ \\
\hline \multirow[t]{2}{*}{ rho } & - & \multicolumn{2}{|c|}{$0.152^{\star *}$} & \multicolumn{2}{|c|}{$0.393^{\star * *}$} \\
\hline & - & & & & \\
\hline \multirow[t]{2}{*}{ sigma 2_e } & - & \multicolumn{2}{|c|}{$0.00447^{* * *}$} & \multicolumn{2}{|c|}{$0.00500^{* * *}$} \\
\hline & - & \multicolumn{2}{|c|}{$(0.000385)$} & \multicolumn{2}{|c|}{$(0.000461)$} \\
\hline $\log L$ & - & \multicolumn{2}{|c|}{346.6773} & \multicolumn{2}{|c|}{291.8016} \\
\hline Wald & _ & \multicolumn{2}{|c|}{$74.72^{\star * *}$} & \multicolumn{2}{|c|}{$33.76^{* * *}$} \\
\hline LR & - & \multicolumn{2}{|c|}{$93.46^{* * *}$} & \multicolumn{2}{|c|}{$30.41^{* * *}$} \\
\hline Hausman & & & $13.05^{\star *}$ & & \\
\hline
\end{tabular}

Standard errors in parentheses. ${ }^{* *} p<0.01,{ }^{* *} p<0.05,{ }^{*} p<0.1$.

In Table 6, the direct effect of command regulations is negatively and inconspicuously, while the indirect plays role on the contrary, which shows that regulations has a certain direct inhibition on local Gtie although, its effects is far less than that of forcing out local innovation resources and stimulating the growth of nearby Gtie. The direct effect of market regulations is not significant, but it suppresses the Gtie in the neighboring region significantly. To deal with the regulations of pollution charges in the region, on the one hand, enterprises will reduce pollution emissions; enterprises will promote the transfer of most of the pollution to the neighboring region significantly. The implementation of public regulations is positive to Gtie in this area significantly, while there are contrary conclusions on neighboring areas. The higher the degree of openness and the more perfect the 
Table 6. The analysis of effects to spatial Durbin Model.

\begin{tabular}{cccc}
\hline Variables & Direct effects & Indirect effects & Total effects \\
\hline ER1 & $-0.00289(0.0864)$ & $0.566^{* * *}(0.172)$ & $0.563^{* * *}(0.183)$ \\
ER2 & $0.572(0.369)$ & $-1.687^{* *}(0.736)$ & $-1.115(0.691)$ \\
ER3 & $1.654^{* * *}(0.591)$ & $0.290(1.296)$ & $1.944(1.337)$ \\
OPEN & $0.934^{*}(0.488)$ & $-4.386^{* * *}(0.955)$ & $-3.452^{* * *}(0.979)$ \\
FDI & $-12.86^{* * *}(4.575)$ & $0.742(10.25)$ & $-12.12(10.33)$ \\
PGDP & $0.0285(0.127)$ & $0.150(0.291)$ & $0.178(0.343)$ \\
\hline
\end{tabular}

Standard errors in parentheses. ${ }^{* *} p<0.01,{ }^{* *} p<0.05,{ }^{*} p<0.1$.

market structure, the more conducive to the inflow of green technology, knowledge and talents. At the same time, due to the fierce regional competition, to certain extent, there is a bottom-by-bottom effect, which makes the competition effects on adjacent regions significant. FDI restrain local Gtie obviously, which indicates that the spillover effect of FDI on local green technology has greatly inhibited the level and ability of local green technology independent innovation. The level of regional economic strength has a positive impact on Gtie inconspicuously. The improvement of economic level has brought about the gradual improvement of residents' consumption concept of green environmental protection and promotes the green market reforms to a certain extent. However, the actual effects of green market reforms on enterprises' green technology innovation is inconspicuously in reality.

\section{Conclusion and Suggestions}

Based on the three-stage value chain framework of technological innovation, this paper measures the efficiency of China's industrial green technological innovation at provincial level, constructing a spatial Durbin model, and examines the spatial effects of different environmental regulations on the Gtie. The results reveal that the Gtie of industry in China has been significantly improved, but the level remains low overall, and the trend regional differentiation has increased; Gtie shows a decreasing spatial pattern in the east, northeast, central and the western region, there is a decreasing distribution pattern from the stage of the technological development, achievement transformation and industrialization. Gtie has significant spatial spillover effects in China. Relying on Durbin model, the total effects are detected; the market, public regulations and openness have significant positive impacts on Gtie, while economic development level has significant negative impacts on it. Command regulations and FDI have no significant impacts; command regulations have significant positive indirect impacts on Gtie, while market regulations and openness have significant negative indirect impacts on Gtie, while other factors have no significant impacts on Gtie.

1) Implementing the Coordination Strategy and Strengthening Regional Exchanges 
On the one hand, the strategic implementation of the western development and the rise of the central region should be promoted unswervingly. On the other hand, regions with high level of Gtie should strengthen the interaction and exchange of technology, knowledge and talents by means of inter-regional industrial transfer and environmental regulations policy coordination, narrowing the technology gap between regions potential gradually, then improving the Gtie level overall.

2) Breaking through Gtie in Diverse Stages to Improve Total Efficiency

As for the main entities of technology development section, science and technology departments of colleges and universities continue to improve their $R \& D$ funding methods and systems, improve funding efficiency, and improve the output of effective green patents. As for the main force of achievements transformation and marketization, on the one hand, the government strengthens cooperation with enterprises, builds green technology test bases and platforms, and improves the efficiency of achievements transformation. On the other hand, the government should guide the construction of regional technology trading market, strengthen the support of green financial credit and tax relief policies for enterprises reasonably, improve the production capacity of green products of enterprises, realize the value of green technology commercialization, and improve the efficiency of green technology innovation as a whole.

3) Adjusting Regulations Dynamically and Improving the Innovation Environment

At present, the situation of environmental regulations in China is dominated by command regulations, and the development of market and public regulations lags behind. The command, market and public regulations influence the Gtie through mandatory standards, price adjustment tools and public opinion supervision respectively. Command and market regulations have their advantages and disadvantages. Therefore, command regulations can prompt enterprises to adopt green technology innovation in a timely and effective manner. Openness is an important factor to affect innovation. The vicious competition of local governments is not conducive to Gtie diffusion, so the vicious competition of local governments should be gradually eliminated, due to the technology crowding effects, FDI has a significant inhibitory effect on local Gtie.

\section{Acknowledgements}

Sponsored by China National Fund for National Social Science Research Project: On the Core theory of Global Layout for China's Strategic Emerging Industry, 17BJL015; WUT Innovation Research Fund: Implementation path and effect evaluation of new energy industry development policy, $2019 \mathrm{III} 185$.

\section{Conflicts of Interest}

The authors declare no conflicts of interest regarding the publication of this paper. 


\section{References}

Andersen, P. C. et al. (1993). Procedure for Ranking Efficient Units in Data Envelopment Analysis. Management Science, 39, 1261-1264. https://doi.org/10.1287/mnsc.39.10.1261

Fried, H. O., Lovell, C. A. K., \& Schmidt, S. S. (2002). Accounting for Environmental Effects and Statistical Noise in Data Envelopment Analysis. Journal of Productivity Analysis, 17, 157-174. https://doi.org/10.1023/A:1013548723393

Frondelm, M., Horbach, J., \& Rennings, K. (2007). End-of-Pipe or Cleaner Production an Empirical Comparison of Environmental Innovation Decisions across OECD Countries. Business Strategy and the Environment, 16, 571-584.

https://doi.org/10.1002/bse.496

Hansen, M. T., \& Birkinshaw, J. (2008). The Innovation Value Chain. Harvard Business Review, 4, 36-49.

Huang, Q., Miao, J. X., \& Li, J. Y. (2015). Research on Spatial Spillover Effect of Technological Innovation Efficiency, of Industrial Enterprises Based on Green Growth. Reform of Economic System, 4, 109.

Li, W. H. (2017). Spatio-Temporal Evolution and Influencing Factors of Green Technological Innovation Output of Provincial Industry in China: An Empirical Study Based on 30 Provincial Data. Journal of Industrial Engineering and Engineering Management, 2, 9-19.

Li, Y., Dang, X. H., \& Han, X. F. (2014). Heterogeneity Effect of Environmental Regulation on Long-Term and Short-Term Effects of Technological Innovation: A Two-Stage Analysis from the Perspective of Value Chain. Studies in Science of Science, 6, 937-949.

Liu, M. Y., \& Yuan, B. L. (2018). Spatial Heterogeneity Effect of Environmental Regulations and Green Innovation Efficiency-Based on the Data of Industrial Enterprises in the Yangtze River Economic Belt. Finance and Accounting Monthly, 12, 144-153.

Liu, S. L., Jiang, X. P., \& Yu, Q. (2015). Characteristics and Evolution of Three Stages of Technological Innovation in China's High-Tech Industry. The Journal of Quantitative \& Technical Economics, 7, 104-116.

Liu, Z. S., Song, D. Y., \& Liu, G. H. (2018). Threshold Effect of Environmental Regulations on Green Technology Innovation Ability of Manufacturing Industry. Commercial Research, 4, 111-119.

Luo, L. W., \& Liang, S. L. (2016). Green Technology Innovation Efficiency and Factor Decomposition of Regional Industrial Enterprises in China. China Population, Resources and Environment, 9, 149-157.

Peng, X., \& Li, B. (2016). Research on Green Transformation of Chinese Industry under Different Types of Environmental Regulations. Journal of Financial Research, 7, 134-144.

Porter, M. E. (1991). America’s Green Strategy. Scientific American, 264, 168. https://doi.org/10.1038/scientificamerican0491-168

Porter, M. E., \& Vander, L. C. (1995). Toward a New Conception of the Environment Competitiveness Relationship. Journal of Economic Perspectives, 9, 97-118. https://doi.org/10.1257/jep.9.4.97

Qiu, Z. L., \& Wang, Y. H. (2018). The Influence of Environmental Regulation on Industrial Ecological Efficiency under the Restriction of Administrative Monopoly-Based on the Test of Dynamic Spatial Durbin Model and Threshold Effect. Industrial Economics Research, 5, 114-126.

Sen, S. (2015). Corporate Governance, Environmental Regulations, and Technological Change. European Economic Review, 80, 36-61.

https://doi.org/10.1016/j.euroecorev.2015.08.004

Tone, K. A. (2001). Slacks-Based Measure of Efficiency in Data Envelopment Analysis. 
European Journal of Operational Research, 3, 498-509. https://doi.org/10.1016/S0377-2217(99)00407-5

Wagner, M. (2007). On the Relationship between Environmental Management, Environmental Innovation and Patenting: Evidence from German Manufacturing Firms. Research Policy, 10, 1587-1602. https://doi.org/10.1016/j.respol.2007.08.004

Wang, F. Z., \& Guo, X. C. (2015). The Impact of Environmental Regulation Intensity on Green Technology Innovation in Resource-Based Industries: An Empirical Test Based on Panel Data from 2003 to 2011. China Population, Resources and Environment, 1, 143-146.

Wang, S. Y., Li, B. B., \& Zhang, S. J. (2018). Research on Environmental Regulation, Spatial Spillover and Green Innovation Based on Spatial Measurement. Areal Research and Development, 2, 138-144.

Wang, W. P., \& Cheng, P. (2013). The Impact of Environmental Policy on Green Technology Innovation-Evidence from Provincial Environmental Patents. Economic Survey, 5, 13-18.

Xu, S. C., He, Z. X., \& Long, R. Y. (2012). The Impact of Environmental Regulation on Green Technology Innovation of Enterprises. Scientific Research Management, 6, 67-74.

Xu, X. Y., Zhao, D. T., \& Hong, J. (2013). An Analysis of the Influencing Factors of Green Technology Innovation-An Empirical Study Based on Chinese Patents. Journal of Central South University (Social Sciences), 2, 29-33.

Yu, Y. Z., \& Liu, D. Y. (2013). Spatial Spillover Effect and Value Chain Spillover Effect of Regional Innovation Efficiency in China-Research on Multidimensional Spatial Panel Model from the Perspective of Innovation Value Chain. Management World, 7, 6-19.

Zang, C. Q., \& Zhang, H. (2015). Spatial Differences in Technological Innovation Effects of Environmental Regulation: An Empirical Analysis Based on Panel Data of China from 2000 to 2013. Macroeconomics, 11, 72-83.

Zhang, J. X., Cai, N., \& Cheng, Y. (2015). Impact of Environmental Regulation on Green Growth Index of Industry in China. China Population, Resources and Environment, 25, 24-31.

Zhang, Q. (2015). An Empirical Study on the Impact of Environmental Regulation on Green Technology Innovation: An Analysis of Provincial Panel Data from the Perspective of Policy Differentiation. Journal of Industrial Technological Economics, 7, 10-18.

Zhao, X. K. (2003). Environmental Protection and International Competitiveness of Industry: Theoretical and Empirical Analysis. Beijing: China Social Science Press. 